DOI: 10.20472/IAC.2017.028.015

\title{
STIG OTTOSSON
}

Norwegian University of Science and Technology, Norway

\section{DEVELOPMENT OF SUSTAINABLE PRODUCT INNOVATIONS}

\begin{abstract}
:
Today the terms sustainable development and sustainable innovation are often used. But what is meant by these terms, other than that they in some ways are connected to the terms "green" and "ecological"? Studying the literature on the topic leads to the conclusion that there is no precise or established definition of sustainable innovation, sustainability and sustainable development.

A conclusion in the paper is that we now need to focus on how to develop new sustainable product innovations, and for these, product development is the most important element as the solutions will affect the environment during the whole Product Life Cycle of the products. Another conclusion is that Dynamic Product Development (DPD ${ }^{\mathrm{TM}}$ ) is a model that seems to satisfy the different definitions on sustainability that have been proposed.

The result of a product development project is based on the product developer's knowledge, experience, and ability. The leadership of an entrepreneur (or intrapreneur) is also important for the level of sustainability of an innovation that is achieved. Therefore, the product developers and entrepreneurs need to be educated in a broader perspective than is common in the technical field today. The product developers must also be monitored in the actual work situation to ensure that new products that are not sustainable are not being marketed. This, in turn, calls for a similar, broader perspective in management education.
\end{abstract}

\section{Keywords:}

Innovation; innovation process; innovation project; sustainability; sustainable innovation.

JEL Classification: A00, C51, C63 


\section{Introduction}

The terms "sustainability", "sustainable development", "sustainable solutions", and "sustainable innovations" are frequently used, for example, in marketing and sales situations. These terms usually represent positive characteristics.

This paper discusses the background of the terms "sustainable" and "innovation". The focus is mainly on how to develop new products from the point-of-view of their environmental impact 'from the cradle to the grave'.

\section{Theory}

"Sustainable Innovation" includes two terms that are popular, but rather unclear. Here, they will be discussed individually, leading to solutions for carrying out sustainable product development.

\section{History of "sustainability"}

From our investigations (Ottosson et al, 2016) we found that the popularity of the term "sustainable" started with the report, "Our Common Future", also called the Brundtland Report, which was released in 1987 by the World Commission on Environment and Development (WCED). The report stated that development only is sustainable if it "meets the needs of the present without compromising the ability of future generations to meet their own needs". A popular simplifying picture, based on the Brundtland Report, is shown in Figure 1. Note that there is no focus on how to develop sustainable solutions, but only depicts what is wanted from the solutions.

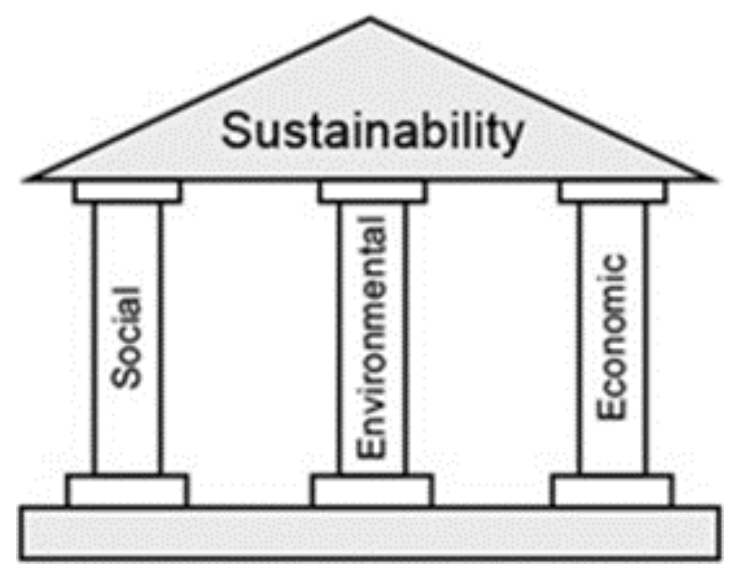

Figure 1: The Three Pillars of Sustainability (Figure from ("The Three Pillars of Sustainability,")

In 1989, the non-profit organization, The Natural Step, was launched (http://www.thenaturalstep.org). It proposed four sustainability principles, based on the principles that in a sustainable society, nature shall not be subject to the systematic increase of:

1. concentrations of substances from the earth's crust (such as fossil CO2 and heavy metals); 
2. concentrations of substances produced by society (such as antibiotics and endocrine disruptors);

3. degradation by physical means (such as deforestation and draining of groundwater tables);

4. structural obstacles to people's health, influence, competence, impartiality and meaning.

The Natural Step also proposed a four-step procedure to accomplish sustainable development. However, their model presents a strict business viewpoint for which there is no guidance on how to develop sustainable products and solutions.

Since1995, the concept of Dynamic Product Development - DPD ${ }^{\mathrm{TM}}$ has been and is being developed (Ottosson, 1996). The focus was initially on how to develop new products in a responsible and efficient way. The core was a user-centered design taking society's demands as well as business' demands into account in an integrated way. In DPD ${ }^{\mathrm{TM}}$, the three outer demands for the product developers are established as: satisfy "performance", "cost", and "development time" set for each development project (see Figure 2).

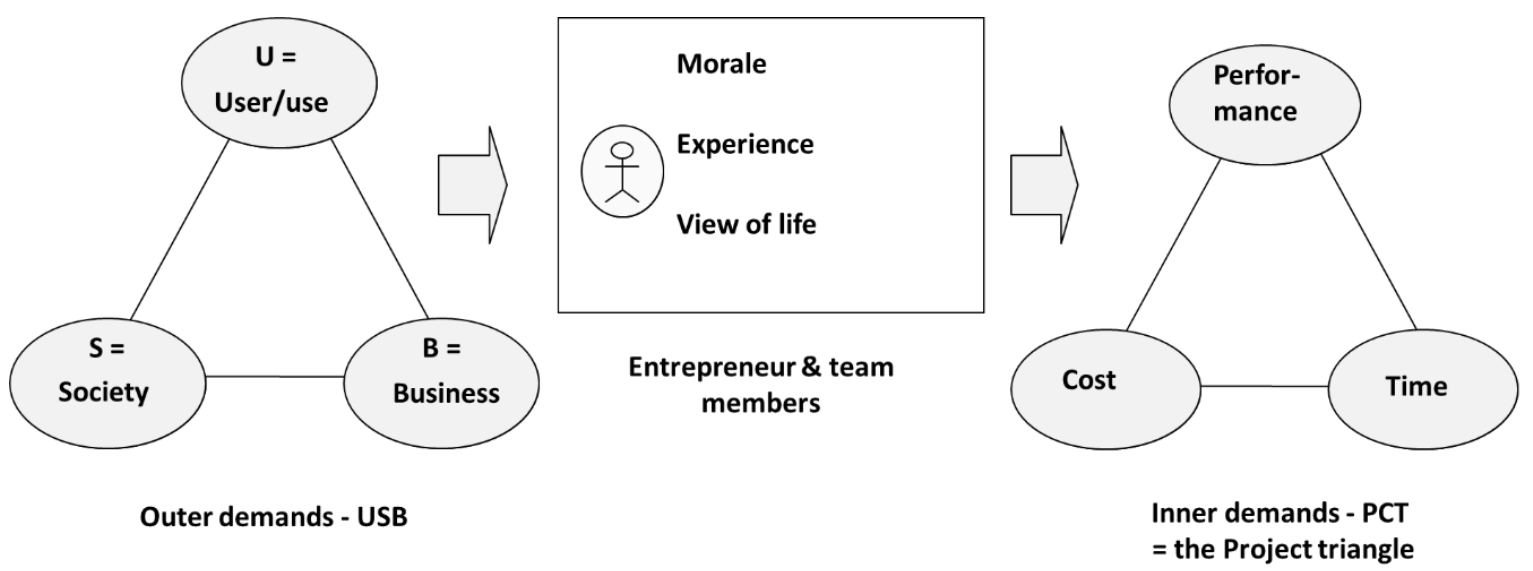

Figure 2: The DPD ${ }^{\mathrm{TM}}$ view of satisfying different demands in the development process (Ottosson, 2009)

Nowadays, it is becoming more and more accepted that sustainable development cannot be defined once and forever. It is a term that can be perceived differently, depending on the area of its application and goals of those applying it. "Sustainable development has always been a 'flexible' concept interpreted in many different ways" (Kambites, 2014). Another useful "assumption is that sustainable development is based not on economic, social, ecological, or institutional dimensions, but rather on their system seen as an integrated whole" (Ciegis, Ramanauskiene, \& Martinkus, 2015). 


\section{Sustainable product development}

There are many factors affecting the development of new products. Figure 3 shows some background issues and considerations to explore when starting the development of a new product.

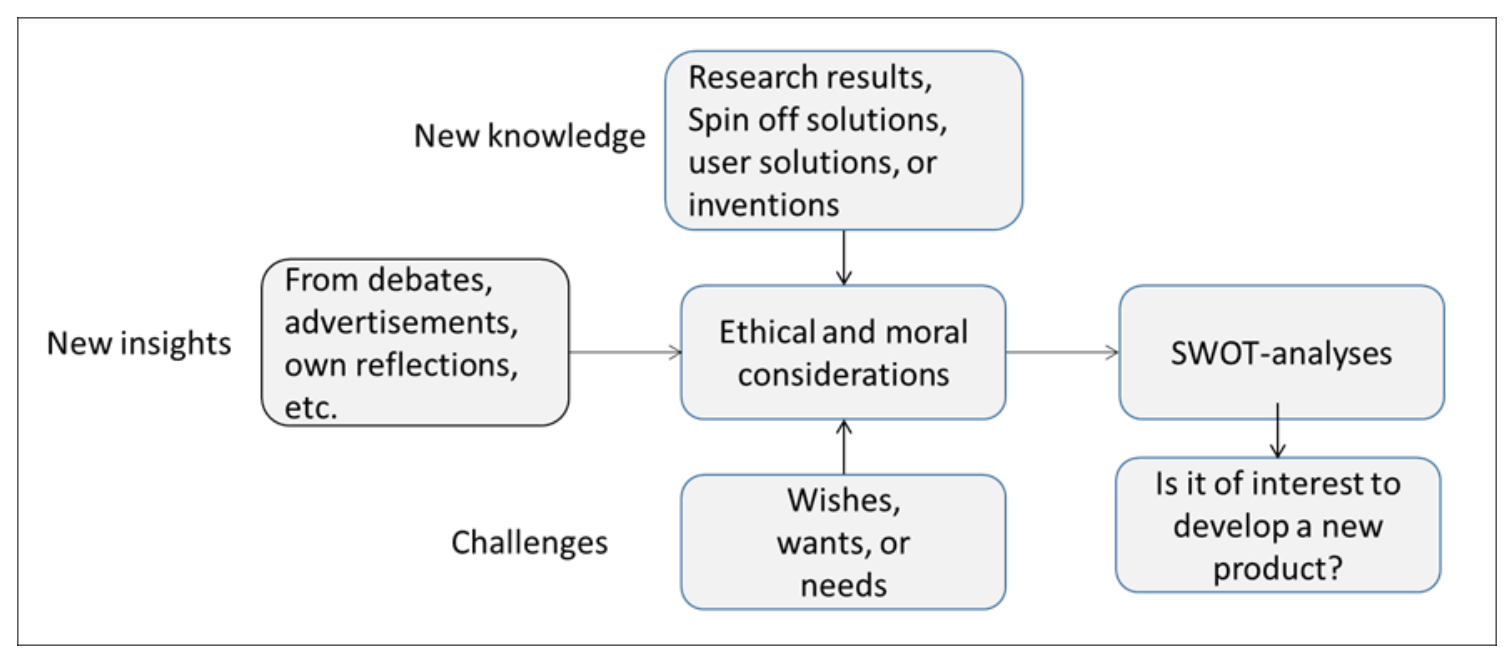

Figure 3: Some background issues and considerations to explore when starting the development of a new product (Ottosson, 2009)

The entrepreneur/project leader and the product development team (c.f. Figure 3) will strongly influence the environmental impact during the whole Product Life Cycle of the product and the supplementary products that the primary product may need to function as intended. Figure 4 shows the recommended actions to develop a sustainable product solution. The bold arrows indicates the environmental impact from a product during its Product Life Cycle. The numbers in the figure refer to:

1. Based on the intended user and the use of the product, seek to enhance safety and quality of life from the use of the product.

2. Decrease the resource utilization and the costs throughout the whole PLC depending on the initial quality and price of the product and its variants.

3. Minimize the negative impact on the environment throughout the PLC.

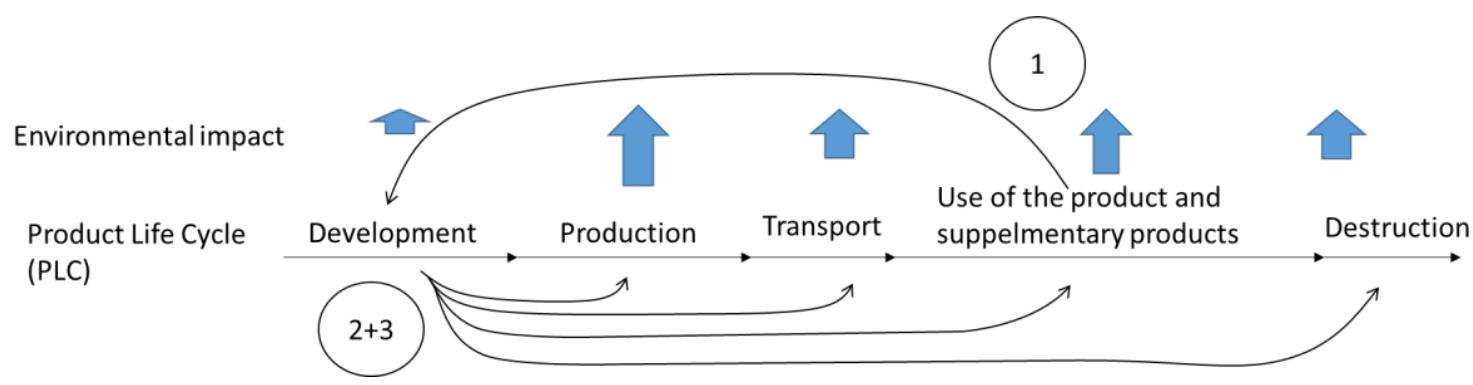

Figure 4: Actions to develop a sustainable product solution (Ottosson, 2016) 
The decision-making tasks in the product development process (e.g., the choice of solution principles or the specification of materials and geometry) are often difficult to determine because the basic objectives (such as cost, function, and quality) are interdependent. This is the reason why the approach/concept of "Design for X - DfX" was proposed in the early 1990's (Hubka, 1995). At that time, DfX was defined as "all endeavors towards making the right decisions in the product development process on basis of a sufficient and universally applicable knowledge basis" (Huang, 1996). Because there are both objectives that support each other, and others that compete against each other in the development process, DfX provided "a systematic guidance for making decisions in product development related to products, processes and plants" (Bauer \& Meerkamm, 2007). Step-by-step, the family of DfX has grown so that, today, there is a large number of X's mentioned and used in engineering design, which can be pictured as a family tree (Bauer, 2003).

With many X's to take into consideration in the development process, product developers have to select and weight different DfX criteria (Bauer \& Meerkamm, 2007). However, the order in which the different DfX's should be carried out in order to achieve an optimal result, when it comes to satisfying demands of the project triangle (cost, time, and properties), has not been adequately discussed. Probably this is mainly because each development process is unique and complex and thereby difficult to handle in a scientific way. However, coming back to the discussions on sustainability, it seems to be reasonable to pursue a user-centered design.

Initially, the focus of product development was on satisfying the needs of business/profit. Thus, Design for Manufacturing and Assembly (DfMA or DFMA) was primarily interested these goals in the development process. Generally, the practice of applying DfMA is to identify, quantify and eliminate waste or inefficiency in a product design. Therefore DfMA can be seen as a component of Lean Manufacturing, e.g., (Holweg, 2007). DfMA is also used as a benchmarking tool to study competitors' products, and as a cost tool to assist in supplier negotiations (Boothroyd et al, 2010).

In the middle of the 1990's, User Centred Design (UCD) and Design for Usability (DfU), as well as Design for Ergonomics (DfEr) began to be broadly used, e.g., (Jordan, 1998). From about 2005, Design for Environment (DfEn) and Sustainable Design also gained increased interest in product development. Today, at least three design methods, DfU, DfEn, and DfEr have to be integrated, when applicable, and are carefully taken into consideration in new product development projects, in order to meet sustainability demands.

Logically, the priority order when developing a new product should be to satisfy the users/use, the society and the business. The simple reason is that without pleased users, there will be no (economically) sustainable business. Without satisfying society demands on sustainable (green) products, there will also be no sustainable businesses. Thus, satisfying user demands in the development process is of prime 
interest, followed by satisfying the sustainable demands on the Product Life Cycle (PLC) chain from 'the cradle to the grave' of the product.

Seen from a user's point of view, a product can have many product values, which can overlap each other (Ottosson, 2009). Central ones are:

- Functional values are dependent

- Perception/sensorial values

- Image values

- Emotional values

- Sustainability values

The different values of a product solution can be satisfied by using the different 'Design for X' possibilities, as shown in Table 1.

\begin{tabular}{|l|l|l|}
\hline Product values & DfX etc. & Abbreviations for \\
\hline $\begin{array}{l}\text { Functional values } \\
\text { Existential values }\end{array}$ & $\begin{array}{l}\text { DfU } \\
\text { DfEx } \\
\text { DfEr } \\
\text { DfSe }\end{array}$ & $\begin{array}{l}\text { Design for Usability } \\
\text { Existential design } \\
\text { Design for Ergonomics } \\
\text { Design for Service }\end{array}$ \\
\hline $\begin{array}{l}\text { Sensorial values } \\
\text { Image values } \\
\text { Emotional values } \\
\text { Existential values }\end{array}$ & DfAe & $\begin{array}{l}\text { Aesthetical design } \\
\text { (industrial design) }\end{array}$ \\
\hline $\begin{array}{l}\text { Sustainability values } \\
\text { Emotional values }\end{array}$ & $\begin{array}{l}\text { DfEn } \\
\text { DfMA } \\
\text { DfQ } \\
\text { DfL } \\
\text { LCA } \\
\text { FTA }\end{array}$ & $\begin{array}{l}\text { Design for Environment } \\
\text { Design for Manufacturing and Assembly } \\
\text { Design for Quality } \\
\text { Design for Logistics } \\
\text { Life Cycle Analyses } \\
\text { Failure Tree Analyses }\end{array}$ \\
\hline
\end{tabular}

Table 1: Design methods to use to achieve different values in product solutions

Good functional values and usability are inter-related. According to (ISO, 1998), usability is "the effectiveness, efficiency and satisfaction with which specific users can achieve specified/particular goals in particular environments".

Still another aspect of the usability of a product is that it should contribute to a barrierfree world for any user. This is called Universal Design, for which seven principles have been proposed (Story et al., 1998). 
To find a functional design that takes into consideration the different usability aspects, the systematics of BAD, PAD, MAD, and CAD has been shown to produce good results. Figure 5 explains the abbreviations, as well as the recommendation to start the work at an abstract and wholeness level, and then to proceed to the detailed and concrete level. The order in which the different activities are carried out is dependent on the products to be developed, the newness desired, time limits, and other issues. The end result is a model, and with additional information, it can be called a product concept.

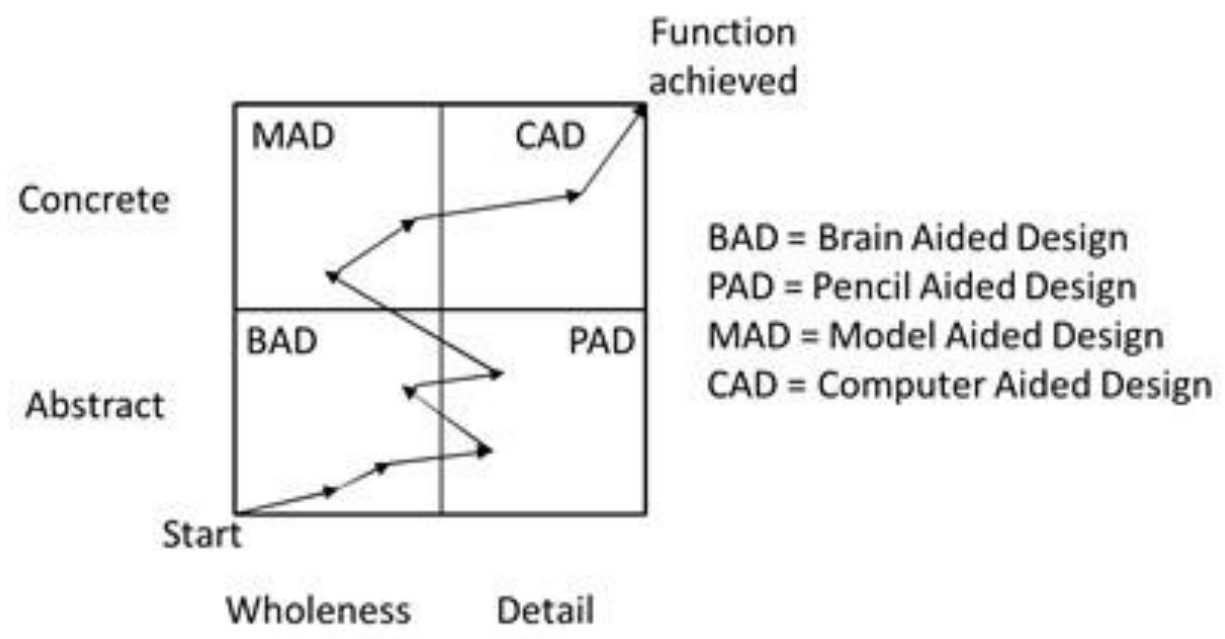

Figure 5 :To find a functional solution from a wish, different steps are needed (Ottosson, 2009)

If the optimal order of the priorities when developing a new product is to satisfy the users/use, the society and the business, DfU must be addressed first, after which the other DfX's can be integrated step by step. Figure 6 shows an illustration of the steps to be taken for the development of a mechanical product. As shown in the figure, new development must always be checked against DfU so that the usability is not hampered. 
Relative time used

$100 \%$

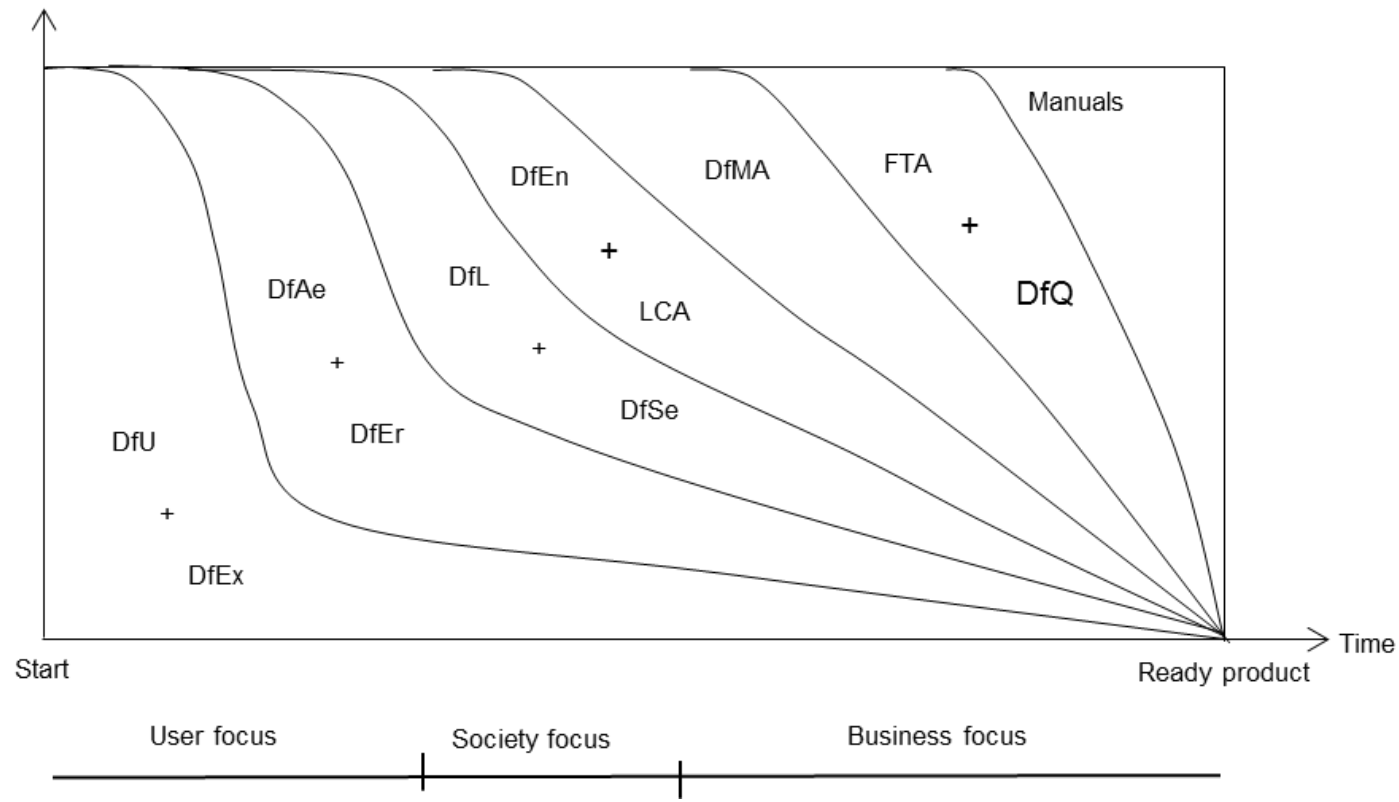

Figure 6: An example of the order in which a new mechanical product can be developed to obtain an optimal result that satisfies many different demands (Ottosson, 2009)

In contrast to what is generally taught - that all demands must be set before commencing with the creation of a concept - we have found in industrial and student projects that a faster and less risky way is to start only with one primary and two or three secondary demands, and then proceed with creating concepts and solutions to satisfy them (Ottosson, 2004). When one or more of the concepts and solutions have been found, more demands can then be added for each of them. These demands can result in the necessity to find new solutions. If a solution does not hold in the test and evaluation phase, it is stopped from further development and documentation is made of the findings and experiences. We have found that using this principle in practical work, which is shown in Figure 7, the work can go ahead at a high speed, resulting in a final concept and a solution that are both well documented. 


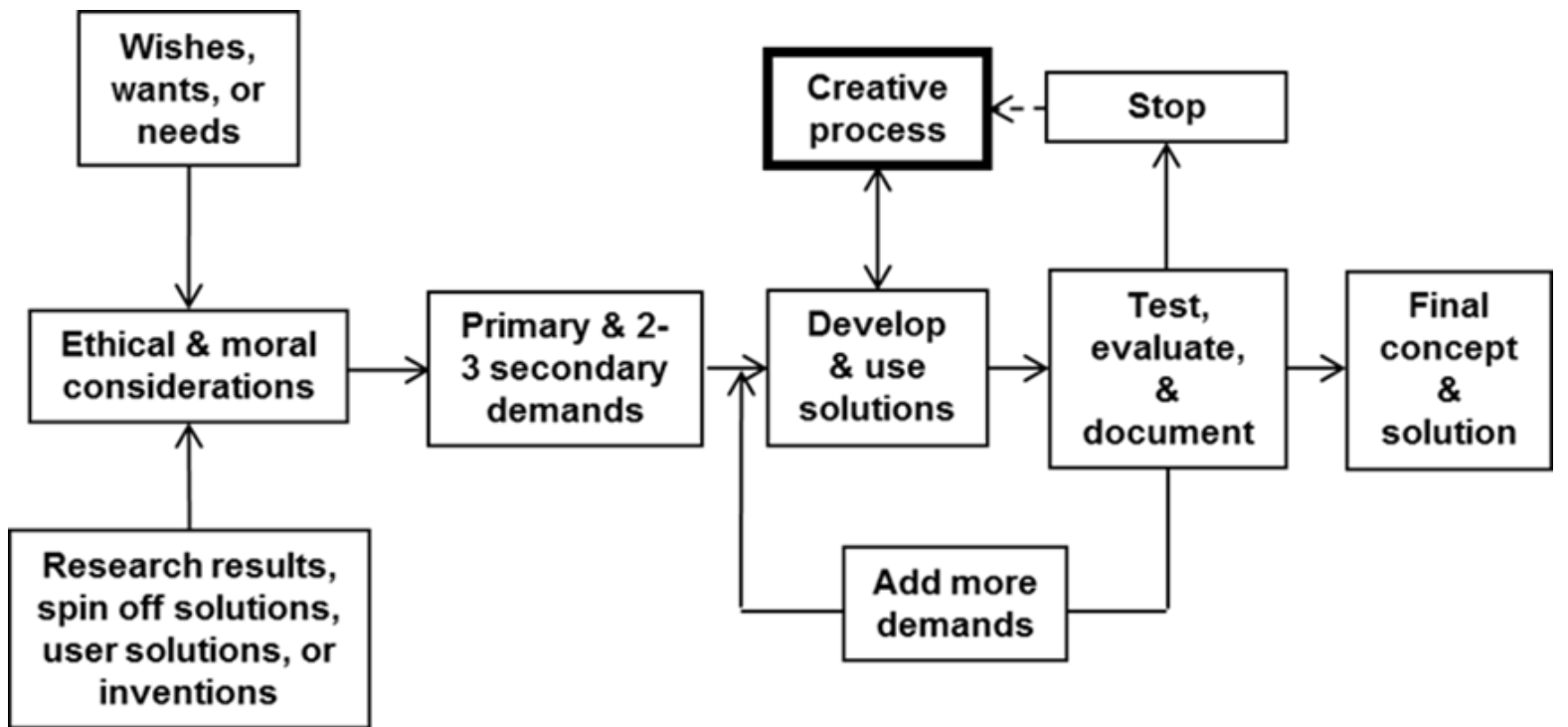

Figure 7: The concept development is an iterative process in DPD ${ }^{\mathrm{TM}}$ (Ottosson 2016)

\section{Innovation theory}

The term "innovation" is apparently derived, from the Latin "novus", which means new or young or novel. Unfortunately, there is no single, accepted definition of the term "innovation". Historically, innovation was defined as the introduction of new elements or a new combination of old elements in industrial organizations (Schumpeter 1934). Thus, his focus was on the actual new ideas or inventions but not on the realization of them. Later, Kanter (1983) defined innovation as the process of bringing any new, problem-solving idea into use. Since then many different definitions have occurred but few have a practical use in mind.

In our times, the terms "Innovation" and "Sustainability", have both become buzzwords, with no single definition. In general, "Innovation" is a positively loaded term that brings hope in difficult times for actors in the private sector, the public sector, the idealistic (non-profit) sector, as well as for whole economies. However, it is seldom explained in terms of how to create successful innovation. Even more unclear is how to develop "Sustainable Innovations" although we might have an intuitive feeling that the expression refers to the development of something good.

To describe what a sustainable innovation is and how it is developed, the following definitions have been proposed (Ottosson et al 2016): a sustainable solution is a solution that has been developed to be a long -lasting, environmentally responsible solution for the provider (the business), the society and also the users; an innovation is a new solution that has been "sold" and is used by more than one user, or that is used in at least one use-situation; the innovation process, done as an innovation project, contains all of the stages from idea generation, development (R\&D) and commercialization, to an implemented solution on the market. 
According to conventional understanding, "Innovations" (independent of a definition of the term) are only done in the private sector (Mulgan, 2007). However, in reality, they have often have been and are being developed in the public sector or in the idealistic (non-commercial) sector. For example, from the public sector we have gained the Internet (CERN), the World Wide Web (DARPA), and new teeth and prostheses made with titanium (Gothenburg University). In the idealistic sector, different open-source solutions have been and are being developed frequently. When the new solutions in these sectors mature, they often 'migrate' into the private sector to become commercial products. This might be why we perceive innovations as something emerging from the private sector.

Thus, innovations are and must be created and developed in all three sectors, although the aims of the work differ. For the private sector, the main aim is to create a sustainable profit. For the public sector, the main aim is to give better service to the people in the society. For the non-commercial sector, the goal is often a better world. All of these activities may encompass a local or global scale.

If we think of "innovation" as a substantive - the end result of a long development project - the mission of an "innovation project" is to carry out all its activities on a micro level in an organization in order to develop, market and sell a new product and/or service with the aim that it will be used or consumed. Today, the selling price is often zero, especially in the non-profit sector. An "Innovation Process" includes the work done following this system, led by the innovation project team of an entrepreneur.

Simply stated, the entrepreneur is like the spider in the innovation process web, in which the sales personnel and market developers must be closely related to the potential customers, while the product developers - and supply chain developers must be closely related to the users and consumers of the products being developed (see Figure 9). Thus, an innovation project is an example of a complex, adaptive social system, encompassing a number of interrelations. 


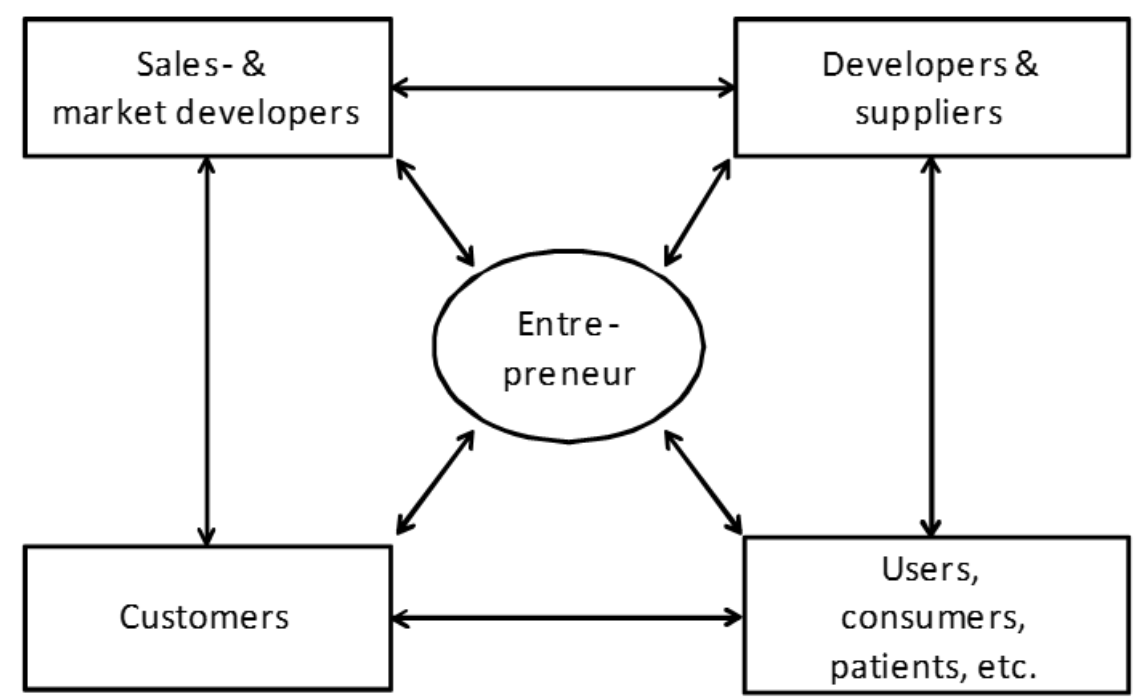

Figure 9: Innovation development takes place in a complex adaptive social system (Ottosson, 2009)

In general, projects are set up to make something unique. Performance demands, cost limits and completion dates are normally set before the project begins. Innovation projects differ from other projects in that they often determine the demands from trial and error, they have no clear finishing dates or rolling cost limits, and they can receive income from the sales of the new products.

A short definition of an innovation covering all sectors of the society might be (Ottosson, 2013):

Innovations are new products and/or services that have been "sold" and taken in use in a local geographical market.

Thus, a new product that has not been bought or adopted is not a new innovation. $A$ new product that has only been acquired but has not been used is also not a product innovation. Note, however, that "acquiring" should be understood here in a wider perspective than just an immediate payment of money. For products/services that are given away free-of-charge, these products/services are often meant to generate other benefits sooner or later, such as revenue, contacts, membership, publicity, or information.

A buyer's/customer's decision to acquire a product is dependent on many things, such as which buyer category the customer belongs to, the customer's present and/or future need of the product, the solution(s) offered by the product, the customer's emotional value of the product, the total price of the product during the time it is in the customer's possession and use, the financial situation of the customer, the estimated further sales price, or the positive or negative value of it at the time of its disposal. The marketers, as well as the sales people, can 'educate' the customers and users to buy/use sustainable products. 


\section{Reflections}

The Brundtland Report and all the various papers and articles that have been written on the subject of sustainability seem to have had the goal of defining the term. The Natural Step has carried the focus forward to "Down to action", which is the theoretical ambition of Dynamic Product Development (DPD ${ }^{\mathrm{TM}}$ ).

Each innovation is unique, which means that each innovation needs a unique business idea or a unique set of ideas to be sustainable at different levels. Figure 11 shows how different views on sustainability are used as inputs in DPD ${ }^{\mathrm{TM}}$, in order to guide product developers to develop sustainable products. The time component is then integrated into the term PCT (Performance-Cost-Time), setting the boundaries of most development projects.

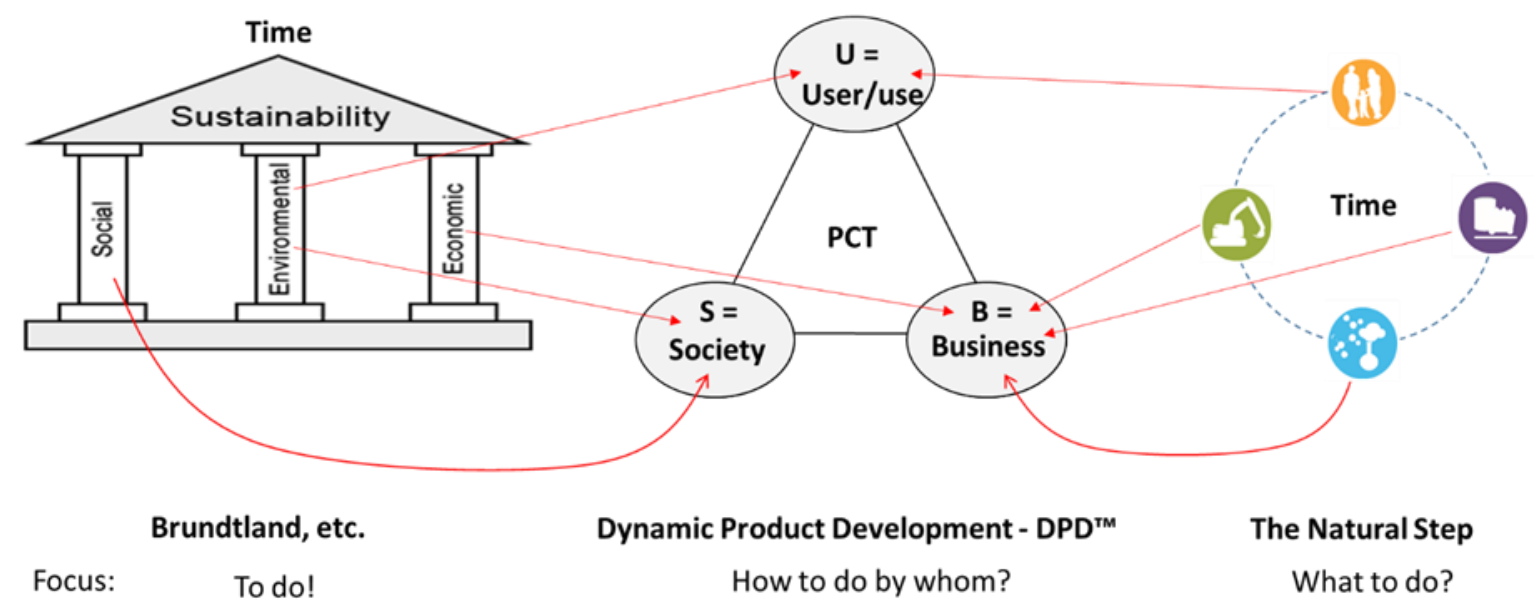

Figure 11: The DPD ${ }^{\mathrm{TM}}$ principles are well positioned for the actual development of sustainable new products, forming the base of new innovations (Ottosson et al. 2016)

Neither "Sustainable Development nor "Innovation" is a well-defined term. To describe what "Sustainable Innovation" is and how it is developed, the following definitions are proposed. A Sustainable Solution is a solution that has been developed to be a long-lasting, environmentally responsible solution for the provider (the business), the society and the users. An innovation is a new solution that has been "sold" and is used by more than one user or that is used in at least one use-situation. The innovation process, carried out as an innovation project, contains all stages from idea generation, development (R\&D) and commercialization to an implemented solution on the market. 


\section{Conclusions}

We now need to focus on how to develop new sustainable innovations, for which the product development is the most important aspect. Dynamic Product Development $\left(\mathrm{DPD}^{\mathrm{TM}}\right.$ ) seems to be a model that satisfies the various definitions of sustainability that have been proposed.

The result of a product development project is based on the product developer's knowledge, experience, and ability. The leadership of an entrepreneur (or intrapreneur) is vitally important to the level of sustainability of an innovation. Therefore, product developers and entrepreneurs need to be educated in a broader perspective than that which is common in the technical field today. Product developers must also be monitored in their actual work situation in order to prevent the marketing of new products that are not sustainable. This, in turn, calls for a similar broader perspective in management education.

\section{References}

Bauer, S. (2003). Design for X-Ansätze zur Definition und Strukturierung. Paper presented at the DFX 2003: Proceedings of the 14th Symposium on Design for X, Neukirchen/Erlangen, Germany, 13.14.10. 2003.

Bauer, S., \& Meerkamm, H. (2007). Decision Making with Interdependent Objectives in Design for X. Paper presented at the Proc. of the 16th.

Boothroyd, G., Dewhurst, P (2010):

Ciegis, R., Ramanauskiene, J., \& Martinkus, B. (2015). The concept of sustainable

Holweg, M. (2007). The genealogy of lean production. Journal of Operations Management, 25(2), 420437.

Hubka, V. (1995). DESIGN FOR - DF. Fertigungsgerechtes Konstruieren. Paper presented at the Beiträge zum 6. Symposium.

ISO. (1998). ISO 9241-11. Ergonomic requirements for office work with visual display terminals (VDTs) - Part 11: Guidance on usability.

Kambites, C. J. (2014). 'Sustainable Development': the 'Unsustainable'Development of a Concept in Political Discourse. Sustainable Development, 22(5), 336-348.

Mulgan, G. (2007). Ready or not? Taking innovation in the public sector seriously. Retrieved from London: http://www.nesta.org.uk/sites/default/files/ready or not.pdf

Ottosson, S. (1996). Dynamic product development: findings from participating action research in a fast new product development process. Journal of Engeering Design, 7(2), 151-169.

Ottosson, S. (2004). Verification of product development methods. Paper prese

Ottosson, S. (2009). Frontline innovation management. Tervix, Göteborg, Sweden (ISBN 978-91. 
Ottosson, S. (2013). Practical Innovation Theory. Tervix, Göteborg, Sweden, 89.

Ottosson, S. (2016): Developing Sustainable Product Innovations, Tervix, Göteborg, Sweden, ISBN ISBN 978-91-639-1980-0

Ottosson, S., Moldavska, A., Ogorodnyk, O., and Skogsrød, T. (2016): What is and how to develop sustainable innovation?, International Conference on Leadership, Innovation and Engrepreneurship (ICLIE), Dubai 20-22 April

Story, M. F., Mueller, J. L., \& Mace, R. L. (1998). The universal design file: Designing for people of all ages and abilities.

The Natural Step. Retrieved from http://www.thenaturalstep.org/our-approach/

The Three Pillars of Sustainability. Retrieved from http://www.thwink.org/sustain/glossary/ThreePillarsOfSustainability.htm

Valentin, A., \& Spangenberg, J. H. (2000). A guide to community sustainability indicators. Environmental Impact Assessment Review, 20(3), 381-392. doi:http://dx.doi.org/10.1016/S0195$\underline{9255(00) 00049-4}$

World Commission on Environment Development. (1987). Our common future. Oxford; New York: Oxford University Press. 